\title{
Employment Situation Analysis and Countermeasures of Contemporary College Students
}

\author{
Shengping Zhang ${ }^{1}$, Dongya Chen ${ }^{* 2,3}$, Wenge $\mathrm{Li}^{1}$
}

1. Department of Electronic Engineering, Shandong College of Electronic Technology, Jinan 250200, China

2. Department of Physics and Information Engineering, Jining University, Qufu 273155, China

3.School of Information \& Electrical Engineering, China University of Mining and Technology, Xuzhou 221116, China

*Correspondence should be addressed to Dongya Chen; corresponding author: chendya@126.com

Key words: college students' employment, employment analysis, psychological guidance

\begin{abstract}
This article has summarized the different age characteristics of university students' employment, focusing on the employment for college students in the 90s. The aspects of society, unit of choose and employ persons, students themselves have been analyzed, and combing with the situation of college students, the right attitude of students towards employment has been helped. Promoting the transformation of university students' employment mentality could solve the problem of college students' employment and provide reference for guiding university students' employment work.
\end{abstract}

\section{Introduction}

College students' employment is to consist with college students' value identity of social labor, to create social value and obtain the corresponding labor remuneration and social activity. In the report of the 17th national congress Comrade Jintao Hu pointed out that employment is vital to people's livelihood, adhere to implement a proactive employment policy, strengthen government guidance, improve the market employment mechanism, expand the scale of employment and improve the employment structure. Improving the ability of college students' employment causes more people to explore and think.

\section{College students' employment characteristics of different era}

College students' employment psychology is closely related with the social development trend and orientation, across the generations under the big wave of social change.

People born in the 70s are growing in the era of change, understanding the importance of opportunity and hard work. They have high knowledge level, innovation ability, mental interdisciplinary talents and skills, and work of regional liquidity increases than before. They began to emphasize individual value. Regardless of whether from cities or countryside student, graduating when the country's reform and opening up period of rapid development, it is easy to accept new things for them without strong ambitions after obtaining employment. Thick knowledge skill accumulation and good foundation for the development make them become mainstay of the enterprise development and nucleus. The 70s has inherent advantages and iron rice bowl.

The $80 \mathrm{~s}$ is a responsibility of generation .In the 80s responsibilities should be under the adjustment of national policy in the growth process. nine years, the college entrance examination policy, work allocation and the welfare housing distribution, make them not have congenital advantages, so pay more attention to practical on academic and career choices, consider in developing responsibility. Of course, putting pressure on themselves bring the lack of patience slowly but surely in the 70s, too much responsibility for rapid promotion and platforms.

It is instant breakthrough in the 90s generation. Various resources platforms emerge endlessly, 
and network, television, mobile phones and information are complicated. As contemporary college students, they are eager to get rid of shoulder the burden of the 80s, independent walk alone and broaden employment concept. 70s career is the traditional concept of career. Accordingly, knowledge precipitates and skills would be thickness, sense of responsibility and coupling of the centripetal force are bottleneck.

\section{The analysis of the causes of contemporary university students' employment after their leaving}

In recent years, as the changes of social environment and employment environment, college students' employment and the problem of choosing become more prominent. There are social policy oriented this problem, also have different policy, environment and accomplishment of a unit of choose and employ persons. But from students themselves, there have been a big change. Discuss from the following several aspects.

\section{Social factors}

Economic growth has slowed, and lower employment is elasticity. In human society, economic growth has fundamental impact on employment. Slowing economic growth, the employment elasticity of GDP is growth. Economic growth to employment pulls gradually reducing. This fundamentally restricts the whole social employment, and university students' employment inevitably has been affected.

Graduate employment directly affect of expansion is a sharp increasing in graduate employment market supply and demand contradiction of total intensified. Due to institutional reform and enterprise workers, absorption capacity of main channel of graduate demand decreases obviously. Obvious contradiction between supply and demand, and enrollment expansion in the short term delay the employment and reduce the effect of social employment pressure. But in the long run, a large continuous expanding enrollment number can quickly double but jobs can't quickly double because of the increase of enrollment. A year after that to enter the job market for college graduates will be greatly increased, and relatively insufficient demand of society, the contradiction of supply and demand quantity may further intensified, so the employment of graduates will be more competitive.

\section{The factors of unit of employ persons}

Compensation factor is one of an important factor in college students leave. Factors include the content of the monetary and non-monetary compensation. Monetary compensation is mainly refers to salary, benefits, pay determine economic and social status, related to his quality of life and activity space, relationship with whether they can support their life very well. When they feel enterprise salary not well paid on behalf of its human resource value, or not to correctly evaluate the contributions to enterprise is likely to choose to leave.

Non-monetary reward for labor is the internal compensation and provides material rewards in non-monetary way. Non-monetary rewards include compensation and promotion of fairness, development opportunities, training opportunities and good cultural atmosphere. Such as students to unit by first-line managers after training, single way. Long engaged in a single operation, no goal setting or positioning inaccurate. Lack of goal oriented in their career prospects cause employees to resign. Or the employing mechanism is not flexible, students flow or choose the limited duty, external inaccessible, internal cannot come out, working enthusiasm is not enough, the student thought development limited, thus offered to resign.

Enterprise has a certain influence on students' departure, for employees, good enterprise atmosphere is a kind of psychological income. Compared with its original campus environment, enterprise culture, human will be relatively complicated and college students to work in the enterprise in addition to the need to obtain a certain amount of material reward, which also need to get some spiritual reward, harmonious enterprise atmosphere is one of them, only in a harmonious enterprise atmosphere to make them satisfied at work. Therefore, in the face of not adapt to the enterprise atmosphere, will lead to college students' departure. Communication between the 
management and the student is not smooth. Management and the lack of long-term, effective communication between students, unit of culture and the concept of inheritance is not enough, easy to cause the students out of context, lack of confidence in the team, offered to resign.

In addition to performance appraisal, or other factors, such as overtime failed to communicate effectively, students understanding the system, examination system and overtime also causes some students offered to resign.

\section{The student's own factors}

It is to point to an individual's feelings, is engaged in the work produced by including working with individual personality, interests, work to conform to the degree of personal ideal and career goals, and perception of job satisfaction, autonomy. For college students born after $90 \mathrm{~s}$, they have independent values, feelings, such traits as comparison pay attention to feeling at work. When feel job content is too boring, lack of autonomy and a sense of achievement, easy to choose to leave.

For the undergraduate of ideals, want to achieve, and with the increase of the number of graduates, unit of choose and employ persons also duly raised the standards of recruitment, especially education standard, originally can work in the undergraduate to graduate, and the original has been increased to undergraduate college students can do the job. University graduates enter the enterprise, and professional ability on the job can not get sufficient play. Value is not implemented. Psychological gap leads to producing for other career options.

Even individual college students internship attracted by higher starting salaries, self-image, self expectations too high, or only to complete an internship, easily choose a career. Confronting students into the same unit, the mutual influence is bigger, the lack of good judgment, individual resigned to turn into a collective behavior.

Second, different students' transition or temporary employment ideas have produced that they work to leave home after a period of time. Different employed most of the students choose a second-tier cities, the employment prospect and the actual employment situation after the gap is bigger, difficult to accept the job and life stress, choose to leave.

\section{The contemporary college students' employment psychological guidance}

Every journey begins with a single step, how to better life is the crucial step, according to the severe employment situation for college students under the new economic situation and the problems of university students' employment analysis, as college students should focus on learning how to self orientation and little detours on the road of development, how to grow up, lay the foundation for the development of the future better.

1. Ask yourself.

What we have: enthusiasm, passion, ambition, and theoretical knowledge. We don't have any experience, confidence, skills and resources

2. The first job is very important to us.

As the first job of life must be well done, well done in the beginning, it was firmly committed has the confidence and courage. Doesn't have to be the first job is going to cause occupational both unity, but can do it, it is very not easy, and good things.

3. To adapt to the environment is the first skill.

Have the courage to change changeable matters, have a heart accept what you cannot change, use wisdom to distinguish the difference. Environment the speed of integration and harmony degree, directly affect the future development.

\section{Prepare everything}

Learn to do everything, touched by others in the daily intravenous drip and details. Remember that people study hard after people lazy, not a manager like live employees will only dry eyes, behind the behavior can reveal more accomplishment and quality.

5. Like it or not, the current job to do the best

Opportunities, good people have a preferred choice. Current work do best, is to choose a better opportunity and right to speak.

6. Personality is very important, character is also very important 
Personality is very important, but it need a positive personality, positive peace of mind as a balance, not to shape personality into the opposite of unknown sleep and complete effect, otherwise will only make people and do not love. No one pay you unabashed individuality, in addition to oneself, personality is based on positive energy.

7. Dry middle school, dry while learning

We learned in school is a basic theoretical knowledge, from theory to practice, there is a long way to go. To do school, dry while learning, learn to one instance and achieve mastery go through a comprehensive study, active learning.

8. Let the teacher like students to do

The teacher is good at looking for work. Believe that two heads are always better then one. Be a teacher of the students like, mentor guidance and development of the growth is always on your arm.

9. How much money or how much money to come up with the customer take depends on the value of the goods he wants to visit the store

Don't always complain about not appreciated, not approved, not to be understood. Seeing if you really want to be appreciated, recognition and understanding. We want to realize the self development is important, necessary and urgent, the development of the self is timeliness, not development sure no, missing the opportunity of development and opportunities, that also not line.

10. No doubt, trust is a kind of quality

Skepticism is need, but also can't discard the trust. To do something, choose to believe their peers or teachers might as well try to believe him once, may be very different.

11. Do the Monkey King to solve the problem

Don't always say "no" in front of the problem. The Monkey King has a strong self-confidence, high enthusiasm, persistent spirit, clear goal. the Monkey King is the ace that make full use of various resources. Iron bars - spell - various gods are all his resources. No cannot solve the problem, the key lies in the choice of the method is correct, some problem can be settled through their skills can, some problems might be solved with the aid of external resources, external force, there is always a kind of external resources to solve the problem.

12. The multi-channel, omni-directional knowledge actively, improving their skills

Is always to have the opportunity to prepare the people, don't do things to do, the cornerstone of the accumulation of today is tomorrow, vision to put more in the long run.

13. Gratitude

Gratitude to the unit has created conditions for us, grateful for colleagues enthusiastic help and support, makes difficult to garland, Thanksgiving is a sign of high emotional intelligence, optimistic life attitude, broaden development horizon.

14. Optimistic attitude, enjoy the pleasure of work and pay

Attitude decides success or failure, optimistic, up is a kind of literacy. Send person rose, the hand have lingering fragrance. It is pleasant to pay, pay you planned, but there is always return.

15. Colleagues, love family, love oneself

Self-discipline self-respect person, love family, cherish who love colleagues, will have more arm strength, will go further, higher, more can relate to that growth is not easy and cherish the happiness of success. Above I in recent years and has entered the society, on purpose of job of college students communicate with each other, hope to have the employment and the employment of college students' help.

\section{Summary}

The rapid development of society provides a variety of resources, but it has brought huge impacts and difficult recognizing. In addition to the trends in the orientation of society, clearing unit of choose and employ persons needs and locating yourself will be carefully considered of the 90s which have the immediately steps into society. We're not rebellious generation but responsible generation, which are bearing the weight of the dream of a generation and the backbone of the next 20 years after all. 


\section{Acknowledgments}

1. Financial support for the work is provided by the Vocational education and adult education in Shandong province "twelfth five-year" plan project named "Investigation and study of vocational colleges employment situation" (2013 zcj028)

2. Financial support for the work is provided by the Teaching reform research project of Jining University 2012 named "Training leading digital signal processing experiment course of practice teaching reform research”(NO.2012JX25)

\section{References}

[1] Zhou Xilin Cao Nannan. Way to raise the capacity of university students' employment analysis [J]. 2012, 3 (6) : 31-33

[2] Yan wanshan. Explore introduction to college students' employment and countermeasures to [J]. 2011, (6) : 86

[3] Li Hanxiong. Human resource strategy management [M].Guangzhou: southern daily press, 2002, 149-160

[4]] Guo Jiyan, Wang Yongxi.2001-2020 China's employment strategy research [M]. Beijing: economic management publishing house, 2001:66

[5] Li Hanxiong. Human resource strategy management [M].Guangzhou: southern daily press, 2012, $171-180$ 